\title{
Dynamic Model of Infected Population Due to Spreading of Pandemic COVID-19 Considering Both Intra and Inter Zone Mobilization Factors with Rate of Detection
}

\section{Mousam Ghosh ( $\sim$ mousamghoshee@gmail.com )}

Ramakrishna Mahato Government Engineering College Purulia, West Bengal, India https://orcid.org/0000-0001-6477-7693

\section{Swarnankur Ghosh}

National Institute of Technology Meghalaya, India

\section{Suman Ghosh}

Techno Main Salt Lake, Kolkata, West Bengal, India

\section{Goutam Kumar Panda}

Jalpaiguri Govt. Engineering College, Jalpaiguri, West Bengal, India

\section{Pradip Kumar Saha}

Jalpaiguri Govt. Engineering College, Jalpaiguri, West Bengal, India

\section{Research Article}

Keywords: Pandemic COVID-19, infected population, intra zone mobilization, inter zone mobilization, rate of detection

Posted Date: May 9th, 2020

DOl: https://doi.org/10.21203/rs.3.rs-28125/v1

License: (c) (i) This work is licensed under a Creative Commons Attribution 4.0 International License. Read Full License

Version of Record: A version of this preprint was published at Chaos, Solitons \& Fractals on January 1st, 2021. See the published version at https://doi.org/10.1016/j.chaos.2020.110377. 


\title{
Dynamic Model of Infected Population Due to Spreading of Pandemic COVID-19 Considering Both Intra and Inter Zone Mobilization Factors with Rate of Detection
}

\author{
Mousam Ghosh ${ }^{1 *}$ \\ Swarnankur Ghosh ${ }^{2}$ \\ Suman Ghosh ${ }^{3}$ \\ Goutam Kumar Panda ${ }^{4}$ \\ Pradip Kumar Saha ${ }^{4}$
}

(ORCID ID- 0000-0001-6477-7693)
(ORCID ID- 0000-0003-3145-5377)
(ORCID ID- 0000-0003-2171-4806)
(ORCID ID- 0000-0002-5567-7241)
(ORCID ID- 0000-0001-8453-5659)

${ }^{1}$ Department of Electrical Engineering, Ramakrishna Mahato Government Engineering College Purulia (Formerly Purulia Govt. Engineering College), Purulia, West Bengal, India.

${ }^{2}$ Department of Electrical Engineering, National Institute of Technology Meghalaya, Shillong, Meghalaya, India.

${ }^{3}$ Department of Electrical Engineering, Techno Main Salt Lake, Kolkata, West Bengal, India.

${ }^{4}$ Department of Electrical Engineering, Jalpaiguri Govt. Engineering College, Jalpaiguri, West Bengal, India.

\begin{abstract}
In present scenario the pandemic COVID-19 is spreading out in most of the widely populated countries. Various researches to restrict the spreading of pandemic COVID-19 are going on in both medical and administrative point of view. The focus has been given in this research keeping administrative point of view in mind. In this paper a dynamic model of infected population due to spreading of pandemic COVID-19 considering both intra and inter zone mobilization factors with rate of detection has been proposed. Few factors related to intra zone mobilization; inter zone mobilization and rate of detection are the key points in the proposed model. Various remedial steps are taken into consideration in the form of operating procedures. Further such operating procedures are applied over the model in standalone or hybridized mode and responses are reported in this paper in case-studies manner. Further zone-wise increase in infected population due to spreading of pandemic COVID-19 has been studied and reported in this paper.
\end{abstract}

Keywords: Pandemic COVID-19; infected population; intra zone mobilization; inter zone mobilization; rate of detection.

\section{Introduction}

Recent outbreak of Corona virus disease or COVID-19 global pandemic comes out as one of the most severe threat to mankind since its first inception in 2019 at Wuhan, China due to a novel virus whose actual source of origin is not identified so far [1-3]. Also, after the inception, this virus spreads rapidly first in China and then in more than 80 countries across the globe [4]. One of the preliminary reasons behind such rapid spreading of the disease has been identified as the contagious nature of the alleged virus which enables the cumulative increase in the number of infections through daily anthropologic activities that require social interactions [5]. Also the stability property of the disease free equilibrium of COVID-19 indicates that proper vaccination for cure from this virus is not yet developed [6]. Therefore, social distancing and rapid detection test have been evolved as the most acceptable preventive measures in recent time [7, 8]. Social distancing is adopted through local and global lockdown by imposing restriction on daily human activities as well as population mobilization $[9,10]$. On the other hand, rapid tests have been performed to detect the presence of the virus among the potential victims and if detected, more stern social distancing is being imposed on the infected persons through quarantine and isolation with proper medication and observatory procedure [11]. But such social lockdown and restriction on human mobilization are detrimental for both social life and mental health of human being as well as for economic growth of the society [1-4]. Therefore, the prediction of probable duration of the lockdown is absolute necessity and needs to be addressed as top priority which requires continuous monitoring of the spreading pattern and timeline of the 
COVID-19 both locally and globally as well as the recovery rate and pattern of the infected population [11]. But the continuously changing genetic structure of the respective virus make prior prediction of the disease difficult and ambiguous which in turn brings delay in devising plan on omitting lockdown fully or partially.

Under such scenario, the demand for precise model to predict the exact nature of the spread of COVID-19 is ever increasing to envisage a proper protective strategy of preventing the aforementioned pandemic. All such predicative models can be broadly divided in two categories. Firstly, the prediction based on statistical analysis which uses collected sample considering different pandemic parameters such as doubling rate [12], basic reproduction factor [13], serial intermission [14] etc. Based on such analysis, several statistical models have been proposed to detect actual inter country infected cases [15] as well as to trace unidentified cases [16], to determine the effects of local and global migration of people [17, 18] etc. Also different advanced statistical techniques have been used to predict the outbreak of corona virus in [19-23].

Secondly, the dynamical modelling has been used extensively to assess the nature of COVID-19 pandemic [24]. In an early attempt, dynamic SIR model was used to predict the final size of COVID-19 pandemic [25]. More advanced SIER model was brought in use to predict different factors associated with the disease and possible measures [26, 27]. In such dynamic models, several factors like transmission process and risk [28], effects of isolation and quarantine [29] etc are also included to make prediction more accurate. An advanced version of SIER model namely e-ISHR model has also been proposed to introduce the effects of time delay in the existing models [30].

Based on the above mentioned works, dynamic model of infected population due to the spread of COVID-19 has been proposed in the present paper considering several real life factors like intra and inter zone mobilization, lockdown before detection, rate of detection and the effects of quarantine after detection. Also the zone-wise increase in infected population due to spreading of pandemic COVID19 has been studied and reported in this paper. Various remedial steps are taken into consideration in the form of operating procedures. Further such operating procedures are applied over the model in standalone or hybridized mode and corresponding responses are reported considering several case studies to indicate that imposing restriction on intra and inter zone mobilization as well as proper quarantine leads to the flattening of pandemic curve. Also the pattern of simulated results obtained here is found to be considerably similar to the patterns of infected population of various countries as reported in the literatures. Proper tuning of the different coefficients or factors associated with the proposed model makes it enable to get the pattern of infected population of any particular country. Various operating procedures have been applied as remedial steps in standalone or hybridized mode.

\section{Proposed Model}

The proposed dynamic model of infected population due to spreading of pandemic COVID-19 is represented in Fig. 1. This model considers three major factors such as intra zone mobilization; inter zone mobilization and rate of detection. In this model a country/state/territory is divided in $\mathrm{N}$ number of zones. At any point of time when it has been realized that such pandemic viral infection is spreading out and the time (day) has been taken as the initial time and total non-detected (implies Nonquarantined) infected alive population on the day has been taken with zone wise distributions.

The parameters which are marked in the proposed model are detailed as follows.

$P_{i}(t)=$ Number of alive non-detected infected population till time $t$ (day) in Zone $i$ (Excluding death / detected with quarantined / cured).

$P_{d q_{i}}(t)=$ Number of detected with quarantined infected population till time $t$ (day) in Zone $i$ (Including death after detection / detected with quarantined / cured after detection).

$\lambda_{i}(t)=$ Distribution factor of $i^{t h}$ Zone at $t^{t h}$ day,

$$
\sum_{j=1}^{N} \lambda_{j}=1
$$

$D_{i}(t)=$ Number of death of infected population but not detected till time $t$ (day) in Zone $i$

$$
\delta D_{i}(t)=\gamma P_{i}\left(t-T_{d}\right)
$$

Where, $\gamma$ is the death factor and $T_{d}$ is the average death time delay in days.

$C_{d t_{i}}(t)=$ Number of cured infected population belongs to detected with quarantined population till time $t$ (day) in Zone $i$.

$C_{n d t_{i}}(t)=$ Number of cured infected population belongs to non-detected population till time $t$ (day) in Zone $i$.

$$
\begin{aligned}
\delta C_{d t_{i}}(t)= & \beta_{d t} \delta P_{d q_{i}}\left(t-T_{c}\right) \\
\delta C_{n d t_{i}}(t)=\beta_{n d t} & \left\{P_{i}\left(t-T_{c}\right)-\delta D_{i}\left(t-T_{c}\right)\right. \\
& \left.-\delta P_{d q_{i}}\left(t-T_{c}\right)\right\}
\end{aligned}
$$


Where, $\beta_{d t}$ and $\beta_{n d t}$ are the factors to become cure and $T_{c}$ is the average time delay to become cure in days.

$$
\delta P_{d q_{i}}(t)=r d_{i}(t)\left\{P_{i}(t)-\delta D_{i}(t)\right\}
$$

Where, $r d_{i}(t)$ represents rate of detection of $i^{t h}$ Zone at time $t$.

$$
\begin{aligned}
P_{i}(t+1)=P_{i}(t) & +\alpha_{m w_{i}}(t) P_{i}(t) \\
& +\sum_{\substack{k=1 \\
k \neq i}}^{N}\left\{\alpha_{m o k i}(t) P_{k}(t)\right\}-\delta D_{i}(t) \\
& -\delta P_{d q_{i}}(t)-\delta C_{n d t_{i}}(t)
\end{aligned}
$$

Where,

$\alpha_{m w_{i}}(t)=$ Enhancement factor of $P_{i}(t)$ due to intra zone mobilization in Zone $i$ at time $t$.

$\alpha_{m o k i}(t)=$ Enhancement factor of $P_{k}(t)$ due to inter zone mobilization from $k^{\text {th }}$ to $i^{\text {th }}$ Zone at time $t$ and $\quad \alpha_{m o}(t)=\alpha_{m o}(t)$ has been considered.

$\lambda_{i}(t+1)=\frac{P_{i}(t+1)}{P(t+1)}$

$P_{\text {total }}(t)=$ Total infected population (with/without detected including death) at the end of $t^{\text {th }}$ day.

$$
\begin{aligned}
P_{\text {total }}(t)=\sum_{j=1}^{N} P_{j}(t) & \\
& +\sum_{j=1}^{N} \int_{0}^{t} \delta D_{j}(t) \\
& +\sum_{j=1}^{N} \int_{0}^{t} \delta P_{d q_{j}}(t)
\end{aligned}
$$

Table 1

Operating procedure

Label

Description

OP-1 Standard lock-down but mobilization happens

OP-2 Inter zone mobilization of few zones are stopped but intra zone mobilization happens

OP-3 Both intra and inter zone mobilization of few zones are fully stopped

OP-4 Rate of detection with quarantined increases 


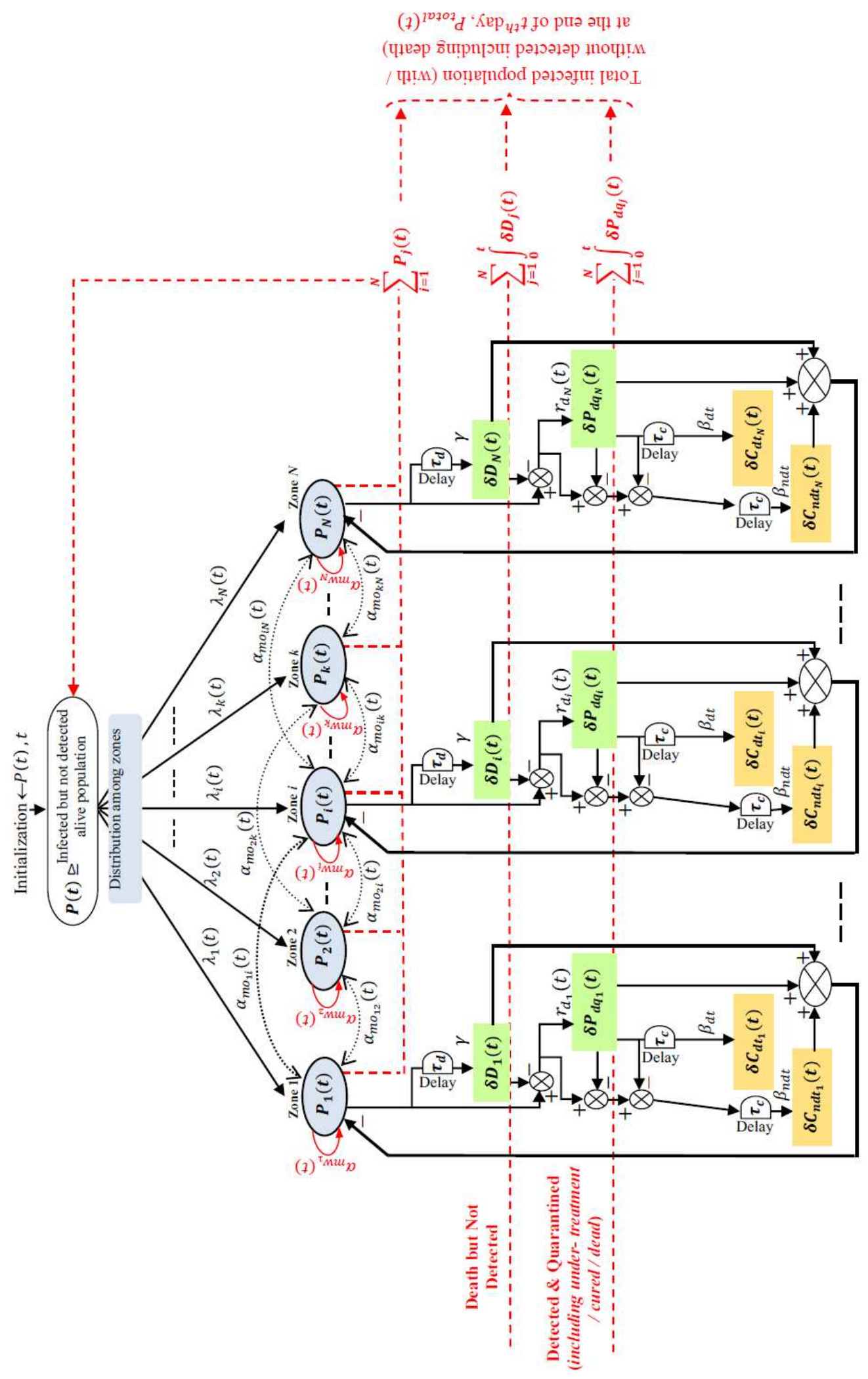

Fig. 1. Block diagram of the proposed model. 
In this model the updation of alive non-detected infected population is done by equation (6) and further the distribution factors can be updated by equation (7). If mobilization of any zone is stopped then in this model the corresponding factors have to be zero. In this model death factor, average death time delay, factors to become cure and average time delay to become cure have also been considered. The average death delay time indicates the delay between infected and death, whereas average time delay to become cure indicates the factor associated will be applied over the delayed infected population and the resulted population does not infect further. In this model the rate of detection also has been considered as a function of time. Further clustering of zones has been considered based on the geographical locations to classify the zones where direct inter zone mobilization may happen. Two adjacent clusters may have some common zones in the region of intersection. Further various operating procedures have been presented in Table 1, which can be applied over the proposed model at any point of time to impose damping over the infected population response. Considering the operating procedures various case studies are simulated and have been reported in the subsequent section.

\section{Simulation Results and Discussions}

The clustering of zones for the simulation is represented in Fig. 2 and random initializations of population are reported in Table 2 . The proposed dynamic model of infected population due to spreading of pandemic COVID-19 has been simulated with Case-1 parameters and the response of number of alive non-detected infected population $\sum P_{i}(t)$ has been represented in Fig. 3. Also the total infected population (with/without detected including death) $P_{\text {total }}(t)$ is represented in the Fig. 3. The responses indicate that the patterns are very much similar to the patterns of infected population of various countries.

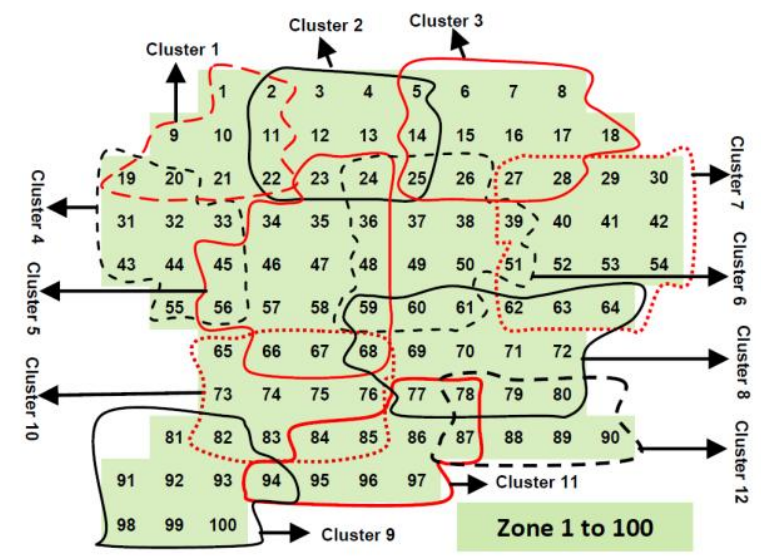

Fig. 2. Clustering of zones considering geographical location.

Table 2

Initialization of population for simulation

\begin{tabular}{cc|cc|cc}
\hline \hline $\begin{array}{c}\text { Zone } \\
\#\end{array}$ & $\begin{array}{c}\boldsymbol{P}_{\boldsymbol{i}} / \\
\boldsymbol{P}_{\boldsymbol{d} \boldsymbol{q}_{\boldsymbol{i}}}\end{array}$ & $\begin{array}{c}\text { Zone } \\
\#\end{array}$ & $\begin{array}{c}\boldsymbol{P}_{\boldsymbol{i}} / \\
\boldsymbol{P}_{\boldsymbol{d q}_{\boldsymbol{i}}}\end{array}$ & $\begin{array}{c}\text { Zone } \\
\#\end{array}$ & $\begin{array}{c}\boldsymbol{P}_{\boldsymbol{i}} / \\
\boldsymbol{P}_{\boldsymbol{d} \boldsymbol{q}_{\boldsymbol{i}}}\end{array}$ \\
\hline 1 & $7 / 2$ & 41 & $8 / 1$ & 72 & $8 / 1$ \\
4 & $10 / 1$ & 42 & $20 / 3$ & 74 & $8 / 2$ \\
8 & $9 / 2$ & 43 & $6 / 0$ & 90 & $8 / 1$ \\
13 & $6 / 1$ & 46 & $5 / 1$ & 98 & $10 / 2$ \\
37 & $6 / 4$ & 61 & $9 / 9$ & Other & $0 / 0$ \\
\multicolumn{4}{l}{$t=20, D_{i}=0$ for all $i$}
\end{tabular}

$t=20, D_{i}=0$ for all $i$

Table 3

Descriptions of case studies

\begin{tabular}{|c|c|}
\hline Label & Description \\
\hline Case-1 & $\begin{array}{c}\text { OP-1 with } \gamma=0.1 \%, \beta_{d t}=\beta_{n d t}=2 \%, r d_{i}=1 \%(\text { for all } i), \alpha_{m w i}=8 \%, T_{c}=5, T_{d}=5, \\
\qquad \alpha_{m o} k i= \begin{cases}0.1 \% & ; \text { if Zone } i, k \notin \text { same cluster } \\
0 & ; \text { else }\end{cases} \end{array}$ \\
\hline & a \\
\hline Case-2 & Case-1 for $t<110$ day, Case-1 with OP-2 for $t \geq 110$ day for zones= 1 to 20 and 61 to 80 \\
\hline Case- 3 & Case-1 for $t<110$ day, Case-1 with OP-3 for $t \geq 110$ day for zones $=1$ to 20 and 61 to 80 \\
\hline Case-4 & $\begin{array}{l}\text { Case-1 for } t<110 \text { day, Case- } 1 \text { with OP-3 \& OP-4 for } t \geq 110 \text { day for zones= } 1 \text { to } 20 \text { and } 61 \text { to } \\
\left.80, r d_{i}=10 \% \text { ( } i=1 \text { to } 20 \text { and } 61 \text { to } 80\right)\end{array}$ \\
\hline Case-5 & Case-1 for $t<110$ day, Case-1 with OP-3 for $t \geq 110$ day for all zones \\
\hline Case- 6 & $\begin{array}{l}\text { Case-1 for } t<110 \text { day, Case-1 with OP-4 for } t \geq 110 \text { day for all zones } r d_{i} \text { (for all } i \text { ) increases } \\
\text { by } 0.5 \% \text { per day }\end{array}$ \\
\hline
\end{tabular}


Further, simulations of various case studies as per Table 3 have been carried out and reported in Fig. 4. It is found that the rate of change of infected population are slowing down for Case- 2 to 6 compared to Case- 1 and in few cases the non-detected infected population are reducing. Again simulations are carried out by applying OP-4 with incremental rate of detection per day basis starting from a certain day and the responses are reported in Fig. 5. It seems that the responses are quite satisfactory compared to Case-1.

Furthermore, for in-depth studies of the proposed model the zone-wise surface maps have been reported in Fig. 6. When the model is operated with the parameters as per Case-1, the zone-wise non-detected infected population are increasing day by day (Fig. 6(a)). But when OP-3 applied to the model from day 110 for the zones 1 to 20 and 61 to 80 as per Case-3, the zone-wise non-detected infected population are reducing for the said zones (Fig. 6(b)).

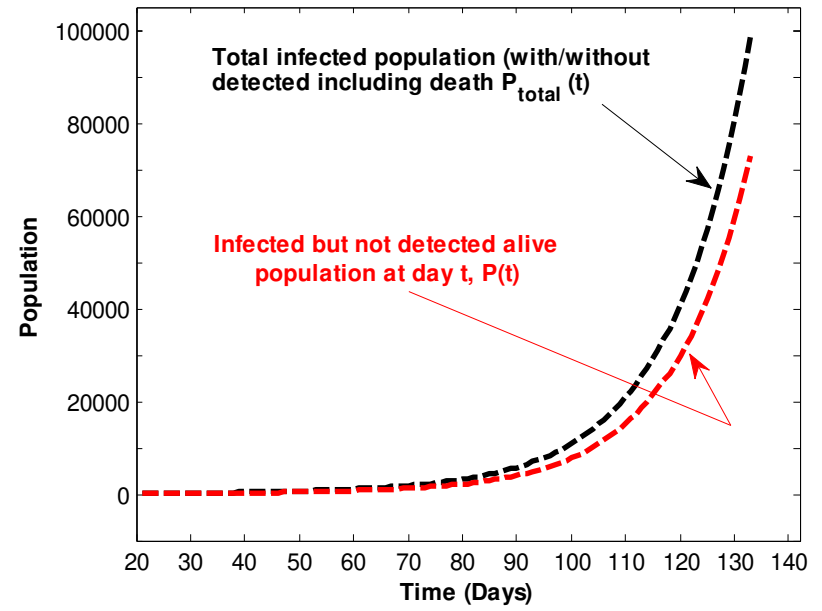

Fig. 3. Total infected population (with/without detected including death) $P_{\text {total }}(t)$ and infected but not detected alive population $P(t)$ with operating procedure OP-1 (Case-1).

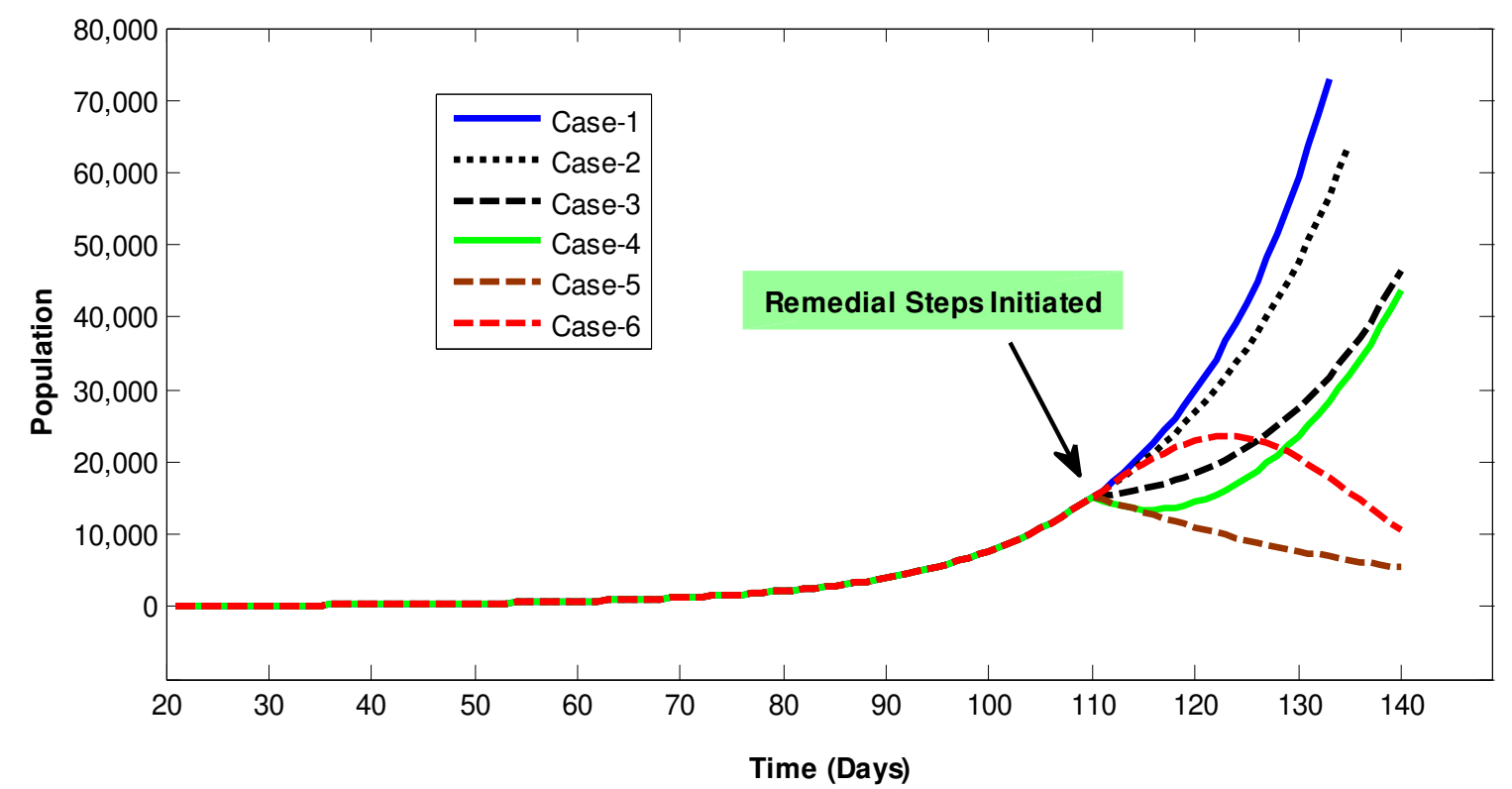

Fig. 4. Comparative analysis of infected but not detected alive population $P(t)$ with various remedial steps initiated from day=110. 


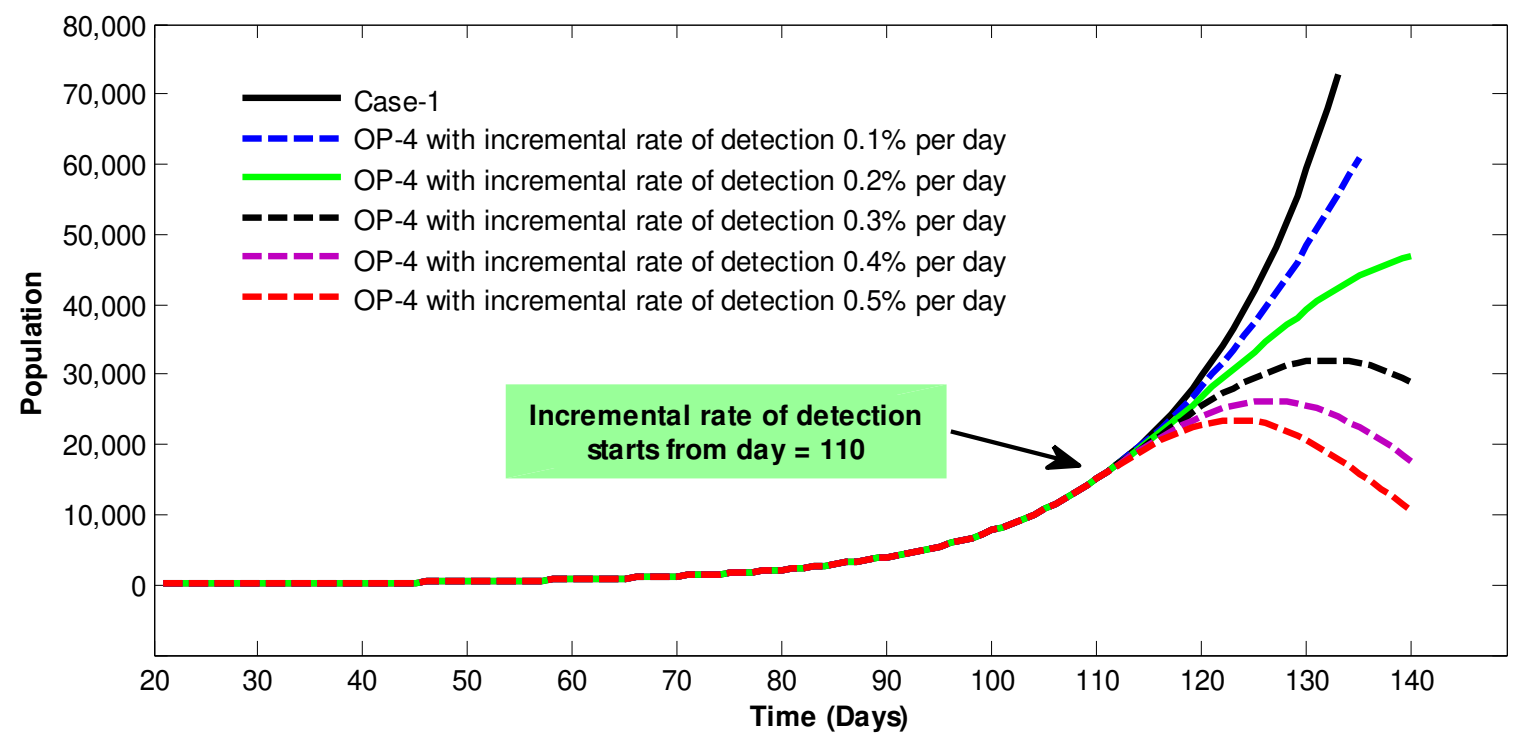

Fig. 5. Comparative analysis of infected but not detected alive population $P(t)$ with various incremental rate of detection initiated from day $=110$.

(a)

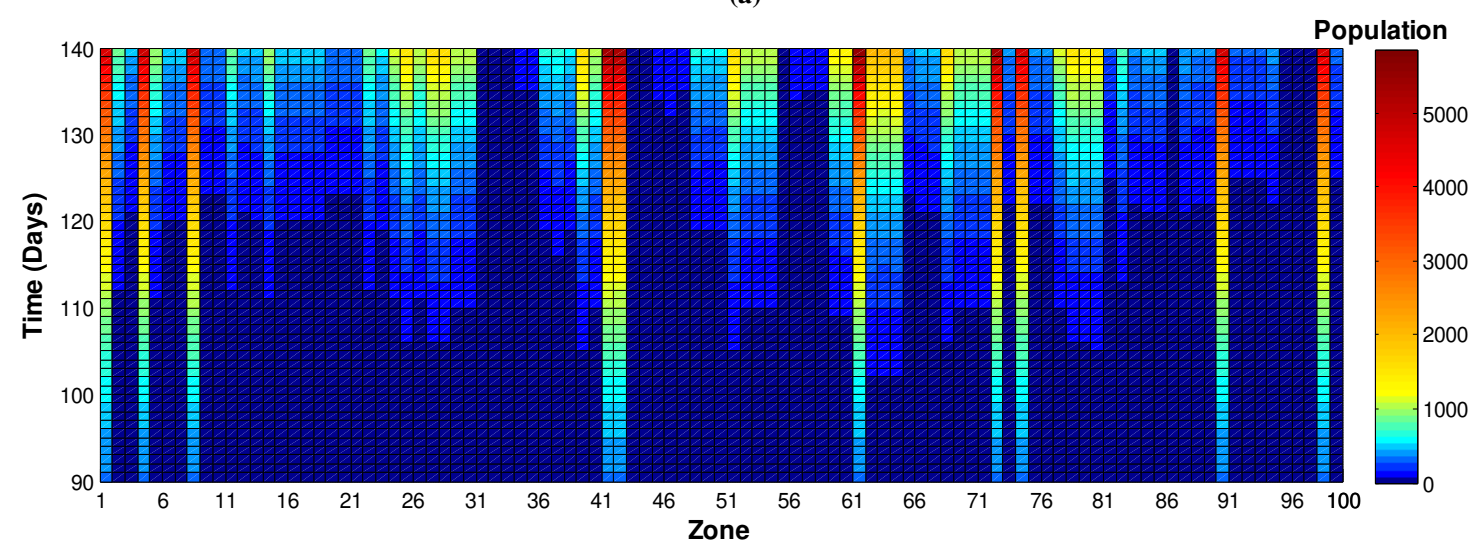

(b)

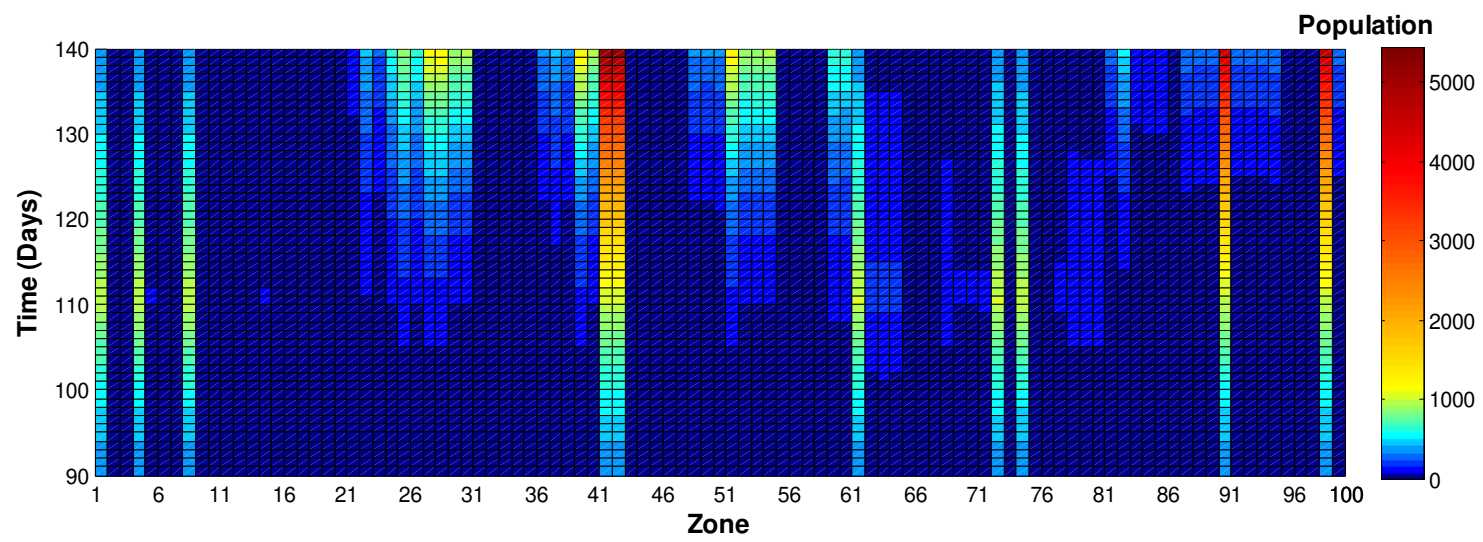

Fig. 6. Zone-wise surface map of infected but not detected alive population $P_{i}(t)$, (a) operating procedure OP-1 (Case-1), (b) operating procedure OP-3 (Case-3).

In view of the reported simulation responses it has to be admired that hybridization of various operating procedures may improve the situation by slowing down propagation of infected population.

\section{Conclusion}

In this paper a dynamic model of infected population due to spreading of pandemic COVID-19 considering both intra and inter zone mobilization factors with rate of detection, have been proposed with various operating procedures. Considering the operating procedures as 
followed in this paper various case studies have been simulated and reported with adequate responses. By observing the simulation responses it has to be admired that the pattern is similar to the patterns of infected population of various countries as reported in the literatures. The coefficients or factors associated with the proposed model are needed to be tuned to get the pattern of infected population of any particular country. Various operating procedures have been applied as remedial steps in standalone or hybridized mode after a certain day and the responses indicate the effectiveness.

Conflict of interest: The authors declare that they have no conflict of interest.

\section{References}

[1] WHO (March 11, 2020) WHO characterizes COVID-19 as a pandemic. on: https://www.who.int/emergencies/diseases/novelcoronavirus-2019/events-as-they-happen

[2] WHO (March 13, 2020). Novel Coronavirus (COVID-19) Situation. on: https://experience.arcgis.com/experience/685d0ace52 1648f8a5beeeee1b9125cd

[3] What you need to know about coronavirus disease 2019 (COVID-19). Centers for Disease Control and Prevention (cdc.gov/COVID19), Atlanta, Geogia, U.S.A. 2020.

[4] John Hopkins Hospital (JHH) (2020). Coronavirus COVID-19 Global Cases by the Center for Systems Science and Engineering (CSSE) at Johns Hopkins. on:

https://www.arcgis.com/apps/opsdashboard/index.ht ml\#/bda7594740fd40299423467b48e9ecf6

[5] Sanche, S., Lin, Y.T., Xu, C.: The novel coronavirus, 2019-nCoV, is highly contagious and more infectious than initially estimated. arXiv preprint arXiv:2002.03268 (2020)

[6] Shen, J.: A Recursive Bifurcation Model for Predicting the Peak of COVID-19 Virus Spread in United States and Germany. medRxiv (2020)

[7] Shen, M., Peng, Z., Guo, Y., Xiao, Y. and Zhang, L.: Lockdown may partially halt the spread of 2019 novel coronavirus in Hubei province, China. medRxiv (2020)

[8] Hellewell, J., Abbott, S., Gimma, A., Bosse, N.I., Jarvis, C.I. and Russell, T.W.: Feasibility of controlling 2019-nCoV outbreaks by isolation of cases and contacts. medRxiv. 2020

[9] Quilty, B.J., Clifford, S., Flasche, S. and Eggo, R.M.: Effectiveness of airport screening at detecting travellers infected with novel coronavirus (2019nCoV). Eurosurveillance. 25, (5), (2020)

[10] Jin, G., Yu, J., Han, L and Duan, S.: The impact of traffic isolation in Wuhan on the spread of 2019nCov. medRxiv (2020)

[11] Lai, S., Bogoch, I.I., Ruktanonchai, N., Watts, A.G., Li, Y., Yu, J., Lv, X., Yang, W., Hongjie, Y., Khan, K. and Li, Z.: Assessing spread risk of Wuhan novel coronavirus within and beyond China, January-April 2020: a travel network-based modelling study. (2020)

Muniz-Rodriguez, K., Chowell, G., Cheung, C.H., Jia, D., Lai, P.Y., Lee, Y., Liu, M., Ofori, S.K., Roosa, K.M., Simonsen, L. and Fung, I.C.H.: Epidemic doubling time of the 2019 novel coronavirus outbreak by province in mainland China. medRxiv (2020)

[13] Zhao, S., Lin, Q., Ran, J., Musa, S.S., Yang, G., Wang, W., Lou, Y., Gao, D., Yang, L., He, D. and Wang, M.H.: Preliminary estimation of the basic reproduction number of novel coronavirus (2019nCoV) in China, from 2019 to 2020: A data-driven analysis in the early phase of the outbreak. International journal of infectious diseases. 92, 214217 (2020)

[14] Nishiura, H., Linton, N.M. and Akhmetzhanov, A.R.: Serial interval of novel coronavirus (COVID-19) infections. International journal of infectious diseases (2020)

[15] Zhao, H., Man, S., Wang, B. and Ning, Y.: Epidemic size of novel coronavirus-infected pneumonia in the Epicenter Wuhan: using data of five-countries' evacuation action. medRxiv (2020)

[16] De Salazar, P.M., Niehus, R., Taylor, A., Buckee, C.O. and Lipsitch, M.: Using predicted imports of 2019-nCoV cases to determine locations that may not be identifying all imported cases. medRxiv (2020)

[17] Chinazzi, M., Davis, J.T., Ajelli, M., Gioannini, C., Litvinova, M., Merler, S., y Piontti, A.P., Mu, K., Rossi, L., Sun, K. and Viboud, C.: The effect of travel restrictions on the spread of the 2019 novel coronavirus (COVID-19) outbreak. Science (2020)

[18] Ding, Y., Luo, S., Zheng, X., Ling, P., Yue, T., Liu, Z. and Weng, J.: Association between population migration and epidemic control of Coronavirus disease 2019. Science China. Life Sciences (2020)

[19] Nesteruk, I.: Statistics based predictions of coronavirus 2019-nCoV spreading in mainland China. MedRxiv (2020)

[20] Zhan, C., Tse, C., Fu, Y., Lai, Z. and Zhang, H.: Modelling and prediction of the 2019 Coronavirus Disease spreading in China incorporating human migration data. [J]. The Lancet, 2020. https://doi.org/10.1101/2020.02.18.20024570

[21] Zhu, H., Guo, Q., Li, M., Wang, C., Fang, Z., Wang, P., Tan, J., Wu, S. and Xiao, Y.: Host and infectivity prediction of Wuhan 2019 novel coronavirus using deep learning algorithm [EB/OL]. (2020-02-02) [2020-02-28]

https://doi.org/10.1101/2020.01.21.914044.

[22] Wu, J.T., Leung, K. and Leung, G.M.: Nowcasting and forecasting the potential domestic and international spread of the 2019-nCoV outbreak originating in Wuhan, China: a modelling study. The Lancet. 395: 689-697, 2020

Majumder, M. and Mandl, K.D.: Early transmissibility assessment of a novel coronavirus in Wuhan, China [EB/OL]. (2020-01-24) [2020-02-28] http://dx.doi.org/10.2139/ssrn.3524675.

[24] Li, Q., Guan, X., Wu, P., Wang, X., Zhou, L., Tong, Y., Ren, R., Leung, K.S., Lau, E.H., Wong, J.Y. and Xing, X.: Early transmission dynamics in Wuhan, 
China, of novel coronavirus-infected pneumonia. New England Journal of Medicine (2020)

[25] Batista, M.: "Estimation of the final size of the coronavirus epidemic by the SIR model." (2020).

[26] Backer, J.A., Klinkenberg, D. and Wallinga, J.: Incubation period of 2019 novel coronavirus (2019$\mathrm{nCoV}$ ) infections among travellers from Wuhan, China, 20-28 January 2020. Eurosurveillance 25, no. $5(2020)$

[27] Xiong, H. and Yan, H.: Simulating the infected population and spread trend of 2019-nCov under different policy by EIR model. Available at SSRN 3537083 (2020)

[28] Tang, B., Bragazzi, N.L., Li, Q., Tang, S., Xiao, Y. and $\mathrm{Wu}, \mathrm{J}$.: An updated estimation of the risk of transmission of the novel coronavirus (2019-nCov). Infectious disease modelling 5 (2020): 248-255

[29] Wu, P., Hao, X., Lau, E.H., Wong, J.Y., Leung, K.S., Wu, J.T., Cowling, B.J. and Leung, G.M.: Real-time tentative assessment of the epidemiological characteristics of novel coronavirus infections in Wuhan, China, as at 22 January 2020. Eurosurveillance 25, no. 3 (2020)

[30] Sijia, L.I., Kun, S.O.N.G., Boran, Y.A.N.G., Yucen, G.A.O. and Xiaofeng, G.A.O.: Preliminary Assessment of the COVID-19 Outbreak Using 3Staged Model e-ISHR. J. Shanghai Jiaotong Univ. (Sci.), 25, no. 2: 157-164, (2020) 
Figures

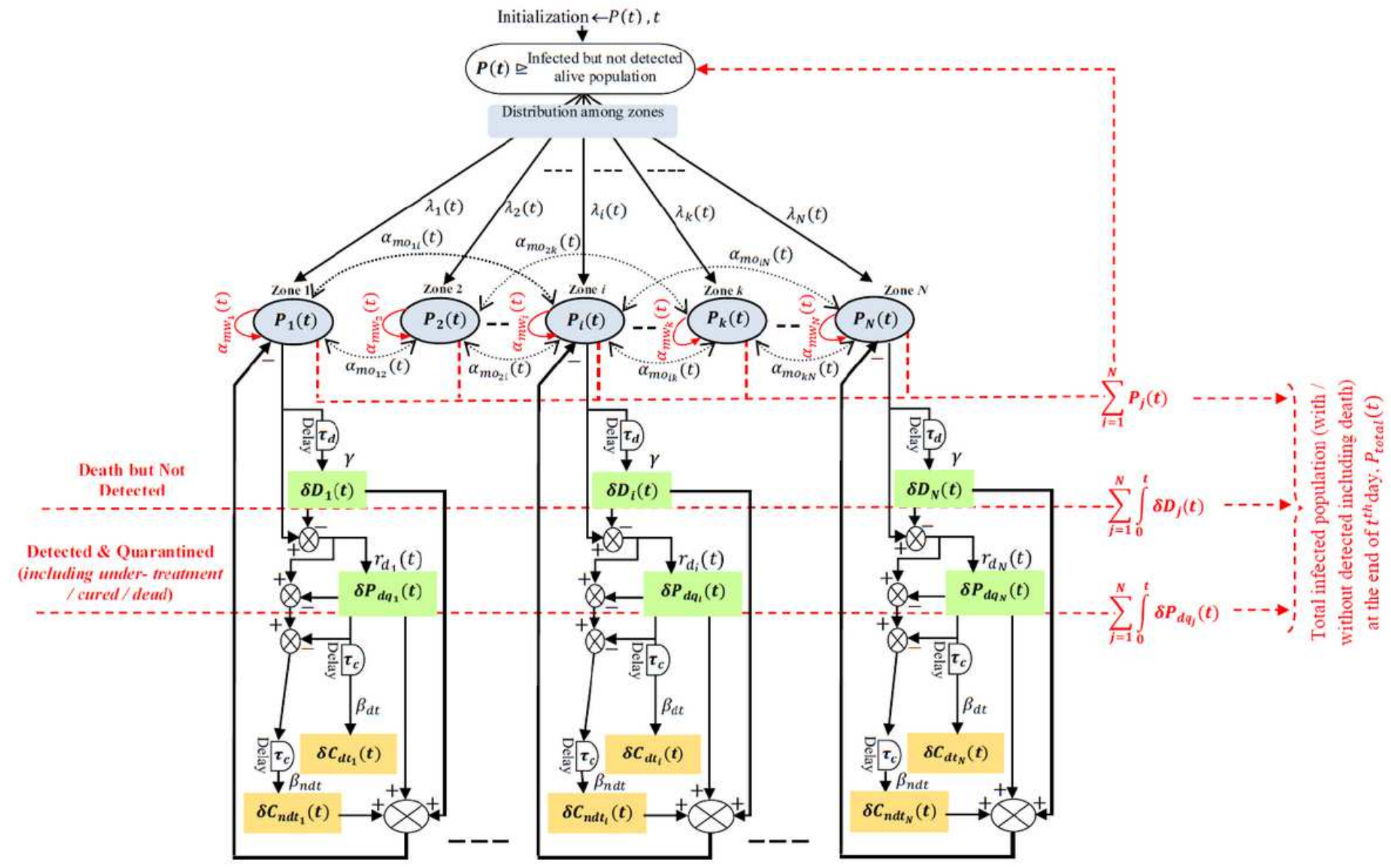

Figure 1

Block diagram of the proposed model. 


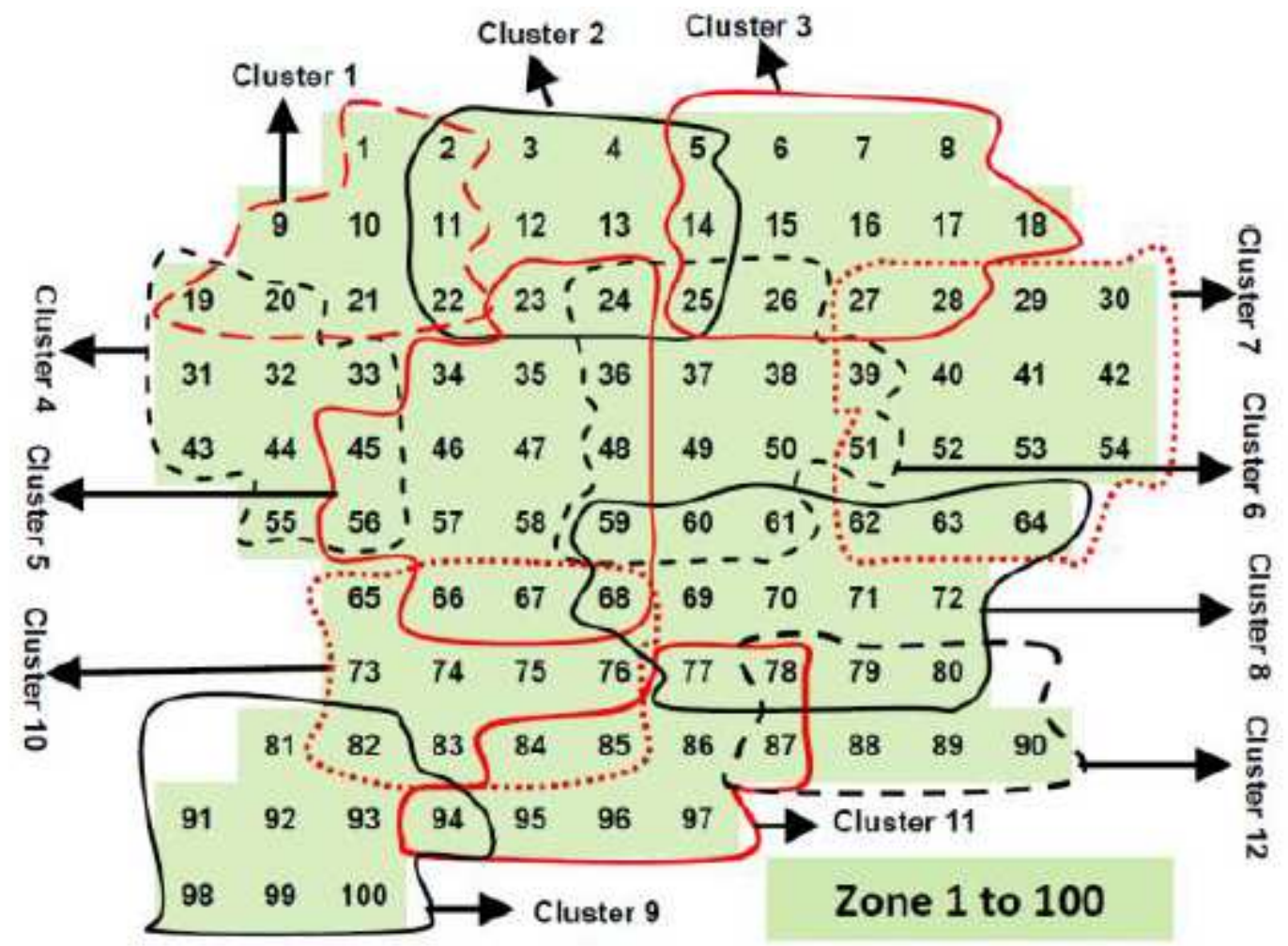

Figure 2

Clustering of zones considering geographical location.

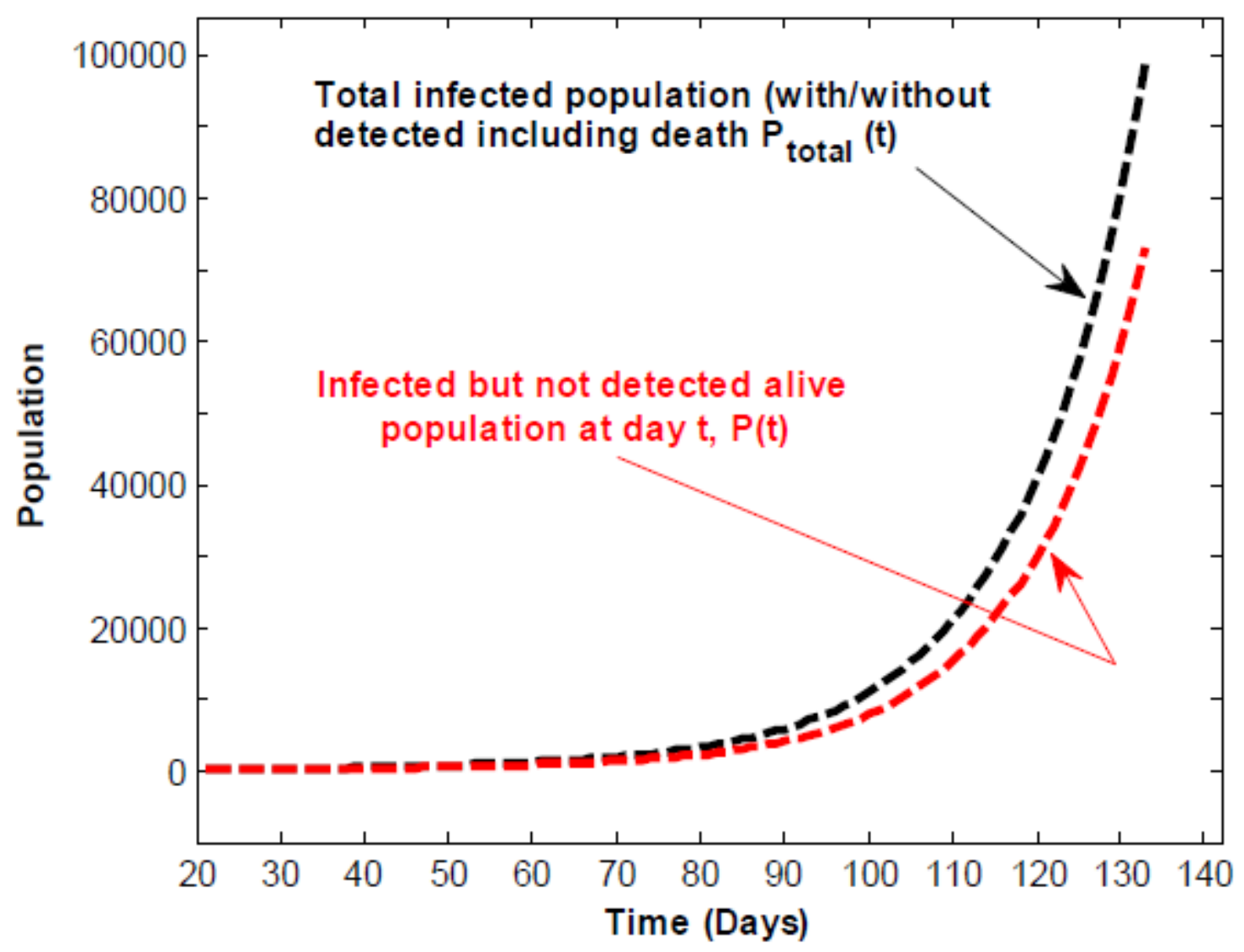




\section{Figure 3}

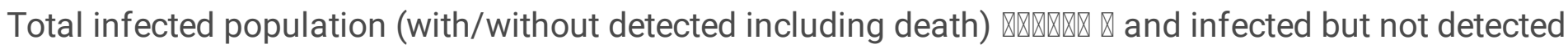
alive population $\mathbb{\nabla}(\mathbb{\nabla})$ with operating procedure OP-1 (Case-1).

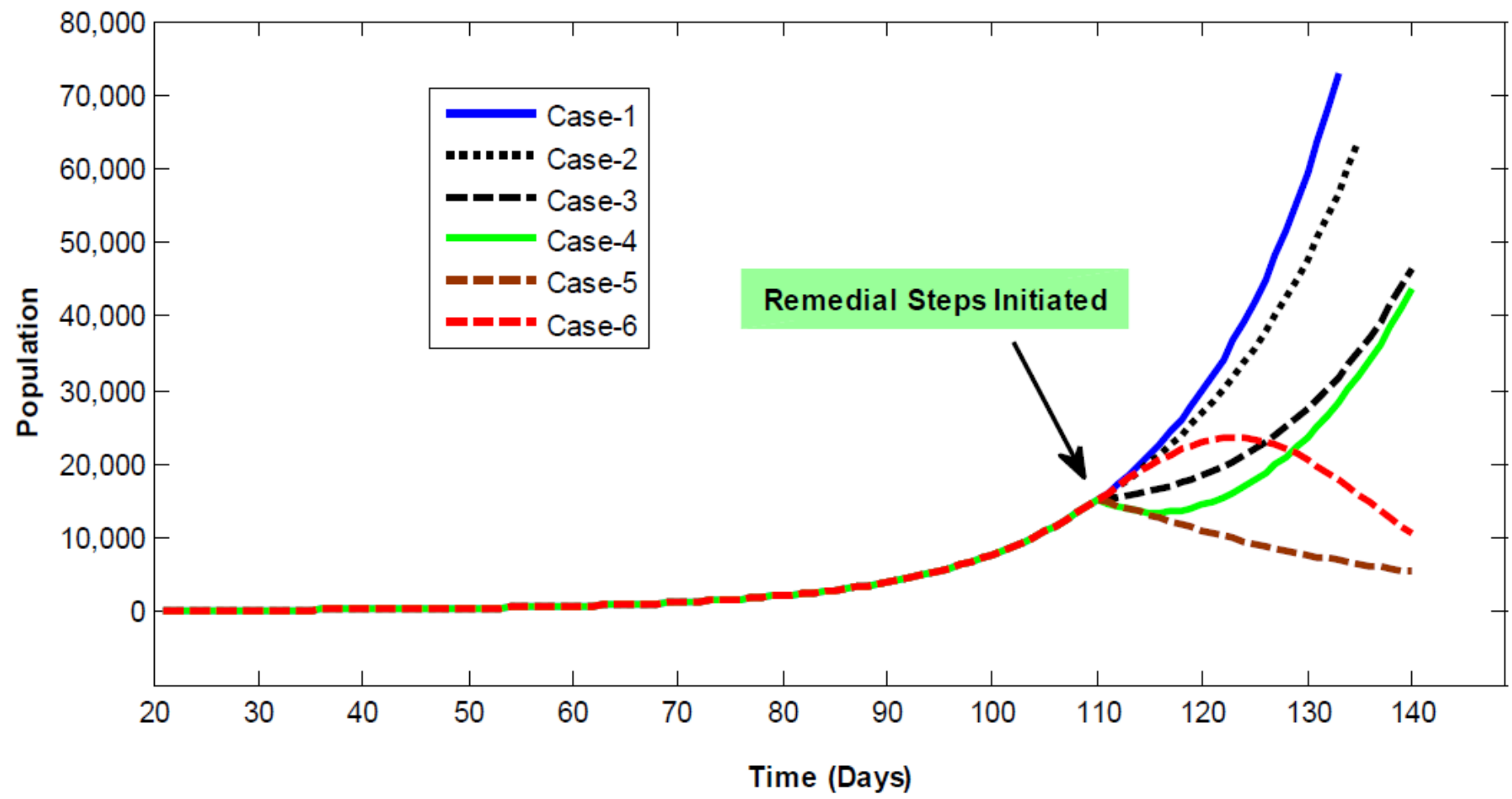

Figure 4

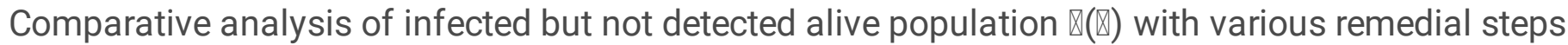
initiated from day $=110$.

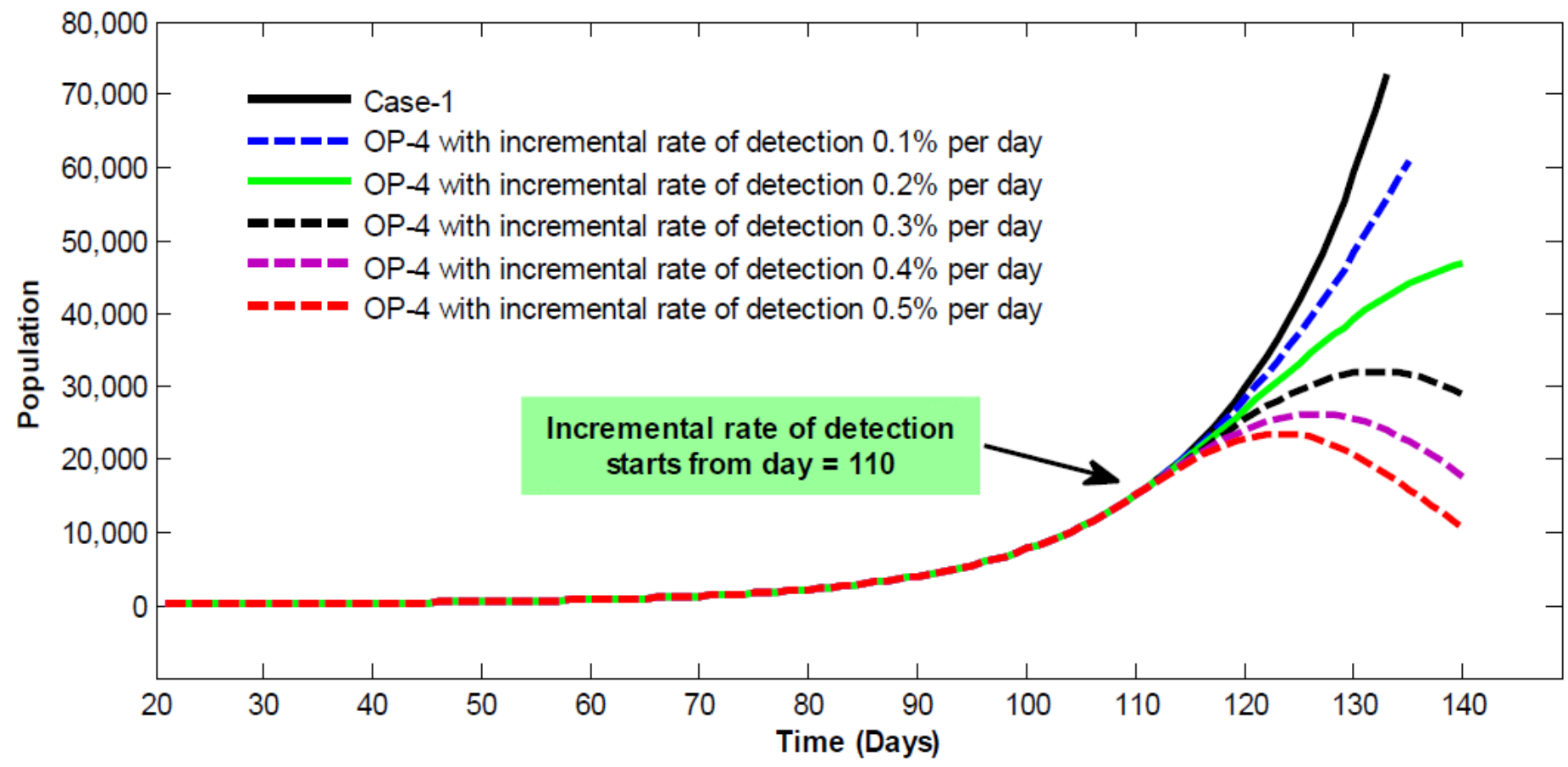




\section{Figure 5}

Comparative analysis of infected but not detected alive population $₫(\nabla)$ with various incremental rate of detection initiated from day $=110$.

(a)

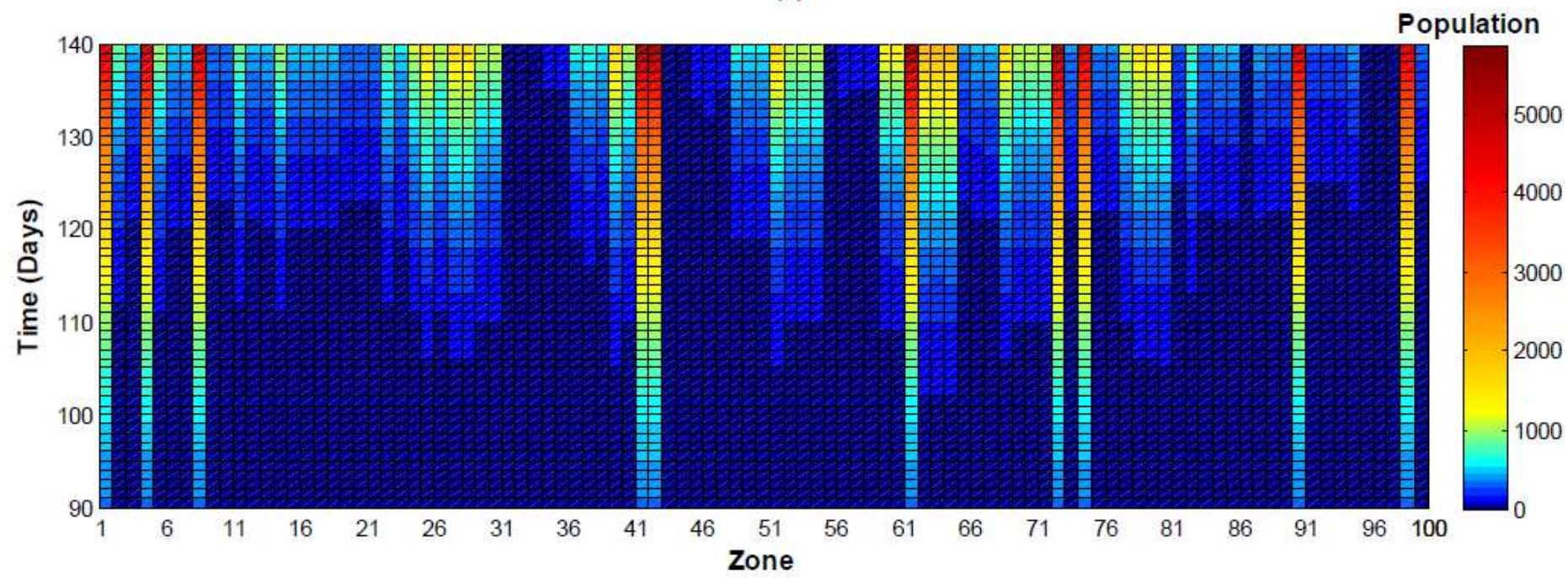

(b)

Population

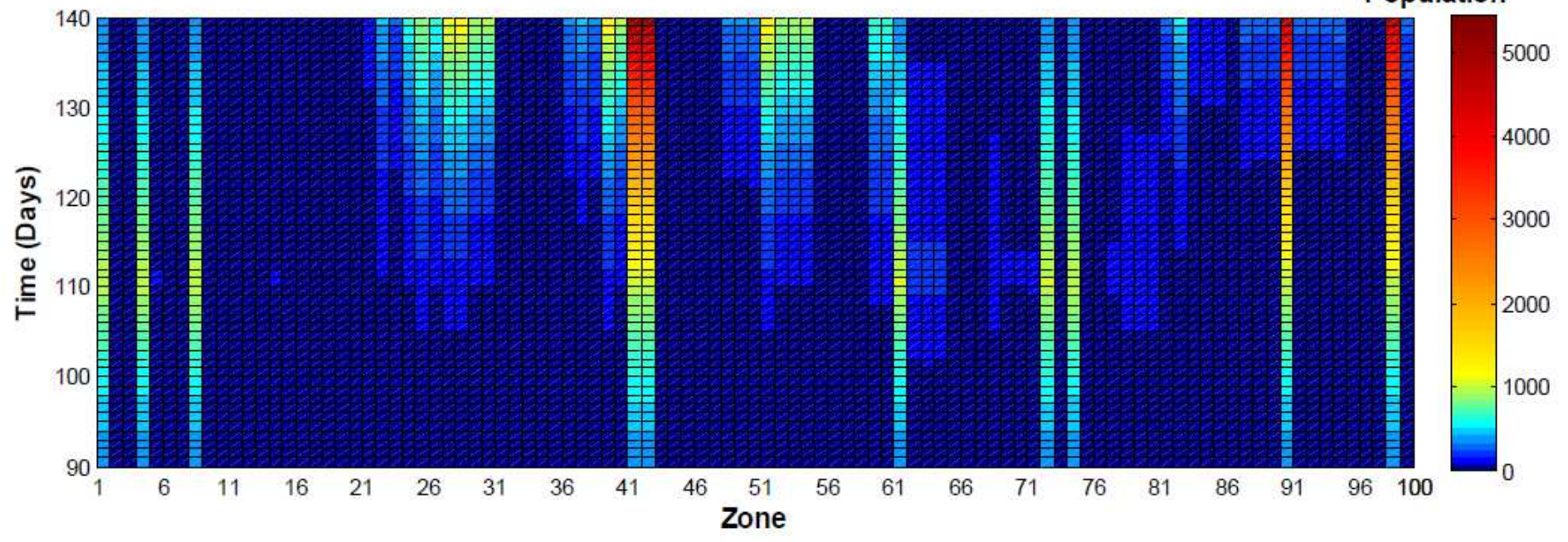

Figure 6

Zone-wise surface map of infected but not detected alive population $\mathbb{Q}(\mathbb{Q}(\mathrm{Q})$, (a) operating procedure OP-1 (Case-1), (b) operating procedure OP-3 (Case-3). 